\title{
Effect of folic acid in a modified experimental model of anorectal malformations adriamycin-induced in rats ${ }^{1}$
}

\author{
Danilo José Fiorindo Faria', Manuel de Jesus Simões ${ }^{\mathrm{II}}$, Luciana Cristina Teixeira ${ }^{\mathrm{III}}$, Angela Tucci Pinheiro Faria ${ }^{\mathrm{IV}}$, Álvaro \\ Edmundo Simões Ulhoa Cintrav, José Luiz Martins ${ }^{\text {VI }}$ \\ DOI: http://dx.doi.org/10.1590/S0102-865020160010000004 \\ IMD, Master, Postgraduate Program in Interdisciplinary Surgical Science, Universidade Federal de São Paulo (UNIFESP), Brazil. Concepcion, design \\ and scientific content of the study; surgical procedures; analysis and interpretation of data; manuscript writing. \\ "PhD, Associate Professor, Histology and Structural Biology Division, Department of Morphology, UNIFESP, Sao Paulo-SP, Brazil. Histophatological \\ analysis. \\ IIIBiochemistry, Postgraduate Program in Interdisciplinary Surgical Science, UNIFESP, Sao Paulo-SP, Brazil. Histophatological analysis.

 \\ ${ }^{v} \mathrm{PhD}$, Postgraduate Program in Interdisciplinary Surgical Science, UNIFESP, Sao Paulo-SP, Brazil. Critical revision. \\ ${ }^{v} \mathrm{PhD}$, Full Professor, Department of Pediatric Surgery, UNIFESP, Sao Paulo-SP, Brazil. Conception and design of the study, critical revision, final \\ approval.
}

\section{ABSTRACT}

PURPOSE: To determine the effect of a single dose of adriamycin (ADR) to induce anorectal malformations (ARMs) and determine the effect of folic acid (FA) in this model.

METHODS: Ten female Wistar rats were divided randomly in two groups. Group A - ADR; Group B - FA+ADR. Dams from group $B$ received daily, since two weeks before the pregnancy to the end of pregnancy, FA (50mg/kg) by gavage. Dams from both groups received ADR $(6 \mathrm{mk} / \mathrm{kg})$ by intraperitoneal injection on gestational day (GD) 8 . Their fetuses were harvested by cesarean section on GD21 and were examined looking for ARMs. The thickness of anal stratified squamous epithelium (ASSE) and intestinal epithelium (IE) were analyzed. $\mathrm{p} \leq 0.05^{*}$.

RESULTS: 81 fetuses were harvested. The number of fetuses; number of ARMs; mean $(\Delta \%)( \pm \mathrm{SD})$ were determined to be, respectively: ADR $-41[29 ; 65 \%( \pm 37 \%)]$ versus $\mathrm{FA}+\mathrm{ADR}-40[04 ; 16 \%( \pm 36 \%)](\mathrm{p}=0.05)$. AMRs were significantly lower in FA+ADR group than in ADR group $(\mathrm{p}=0.05)$. The thickness $(\mu \mathrm{m})$ of ASSE $( \pm \mathrm{SD})$ and IE $( \pm \mathrm{SD})$ were measured, respectively: ADR $-[25.98( \pm 0.74)$ and $19.48( \pm 1.68)]$ versus $\mathrm{FA}+\mathrm{ADR}-[24.74( \pm 0.91)$ and $24.80( \pm 0.81)](\mathrm{p}<0.005)$. The thickness of IE was significantly enlarged when FA was given $(\mathrm{p}<0.005)$.

CONCLUSIONS: Single dose of adriamycin on D8 was able to induce anorectal malformations. Folic acid reduces the number and enlarged the IE of ARMs ADR-induced.

Key words: Anal Canal. Anus, Imperforate. Doxorubicin. Folic Acid. Rats. 


\section{Introduction}

Anorectal malformations (ARMs) represent a broad spectrum of congenital anomalies, including anorectal and urogenital sinus defects. The incidence rate is approximately 1 per 5000 live births ${ }^{1}$, occurring most frequently in males. Usually, the spectrum of AMRs presents defects on the terminal hindgut, anus, pelvic floor muscle (PMF) and striated muscle complex (SMC), innervations of PMF and SMC, androgenital and spinal defects. Posterior sagittal anorectoplasty (PSARP) has been proposed as gold standard surgery ${ }^{2}$. Despite various advances in this technique, poor postoperative anorectal functions still remain as major problem. Fecal incontinence, constipation and voiding dysfunction are observed.

ARMs pathogenesis and morphogenesis remains unclear. Different teratogenic drugs have been used to mimic ARMs in rats. Different models of ARMs Adriamycin-induced have been published $^{3-5}$.

Adriamycin (ADR) experimental model is a well established model of foregut anomalies in rats. These models can simulate VACTER association, including ARMs ${ }^{3-5}$.

Good evidence from randomized trials suggests folic acid (FA) reduces the risk for neural tube defects (NTD). Maternal consumption of folic acid before pregnancy and during early pregnancy is associated with a reduced risk for some other birth defects. The rate of ARMs was greater among mothers who did not take folic acid than mothers who took folic acid before pregnancy. Daily maternal consumption of $400 \mu \mathrm{g}$ of folic acid could reduce the risk for $\mathrm{AMRs}^{4}$.

The aim of this study was to determine the effect of a single dose of adriamycin to induce anorectal malformations (ARMs) and determine the effect of folic acid (FA) in this model.

\section{Methods}

Ethical approval was obtained from the Research Ethics Committees of the Universidade Federal de São Paulo prior to the study (Protocol $\left.n^{\circ} 1859 / 11\right)$.

Ten female mature Wistar-EPM rats were provided from the Central Biotery, UNIFESP. Rats were divided randomly in two groups. Group A - ADR and Group B - FA+ADR. One dam from group A died during pregnancy.

Dams from group B received daily, since two weeks before pregnancy to the end of pregnancy, FA $(50 \mathrm{mg} / \mathrm{kg})$ by gavage.
Rats received commercial feed and water ad libitum, under constant environmental conditions of temperature and humidity, with 12-hour day and night cycles using artificial light, automatically controlled. After one night of mating, dams who presented a vaginal smear with the presence of spermatozoids were considered to be potentially fertilized. This was considered to be day zero (GD0) of gestation. Dams were kept in individual cages.

On gestational day (GD) 8, dams from both groups received $\mathrm{ADR}(6 \mathrm{mk} / \mathrm{kg})$ by intraperitoneal injection.

On GD21, dams were anesthetized with $2 \%$ xylazine $(60 \mathrm{mg} / \mathrm{kg})$ and $10 \%$ ketamine $(10 \mathrm{mg} / \mathrm{kg})$ by intramuscular injection. Fetuses were harvested by cesarean section and were initially examined externally looking for AMRs. Dams were sacrificed by cervical dislocation. Following this, fetuses were underwent to exploratory laparotomy to characterize the type of ARMs. Terminal intestine was removed to histological analysis.

Fragments of terminal intestine were fixed in $10 \%$ buffered formaldehyde, dehydrated and embedded in paraffin, stained with hematoxylin and eosin, and examined microscopically. The thickness of anal stratified squamous epithelium (ASSE) and intestinal epithelium (IE) were analyzed.

Non-parametric tests were used when samples tested against normal distribution. Kruskal-Wallis test was used to compare different groups and Mann-Whitney test when comparing two groups. Parametric tests were used in the histological analysis. Thickness was compared using two way Analysis of Variance (ANOVA) and post hoc Turkey test. Significant differences were considered when $\mathrm{p}$ values $\leq 0.05$.

\section{Results}

Eighty one fetuses were harvested. There were 41 fetuses from group A (ADR) and 40 fetuses from group B (FA+ADR).

In the ADR group, the mean weight of dams on GD0 and GD21 was, respectively $221.25 \mathrm{~g}$ and $263.75 \mathrm{~g}$. In the FA+ADR group, the mean weight of dams on GD0 and GD21 was, respectively $229.40 \mathrm{~g}$ and $287.20 \mathrm{~g}(\mathrm{p}>0.05)$. In the ADR group, the mean weight ( $\mathrm{g}$ ) of fetuses \pm standard deviation (SD) was 2.00 \pm 0.49 . In the FA+ADR group, the mean weight of fetuses $\pm \mathrm{SD}$ was $4.94 \pm 0.89(\mathrm{p}=0.01)$.

Statistically significant differences were observed comparing ARMs in 2 groups (Table 1). Folic Acid reduces the number of ARMs ADR-induced $(\mathrm{p}=0.05)$. Typical anorectal area, in rats, was evidenced in Figure 1. ARMs were highlighted in Figures 2 and 3 . 
TABLE 1 - Presence of ARMs.

\begin{tabular}{ccccc}
\hline Group & Fetus & ARM & Mean $(\Delta \%)$ & SD $(\%)$ \\
\hline ADR & 41 & 29 & $65 \%$ & $37 \%$ \\
AF + ADR & 40 & 4 & $16 \%$ & $36 \%$ \\
\hline
\end{tabular}

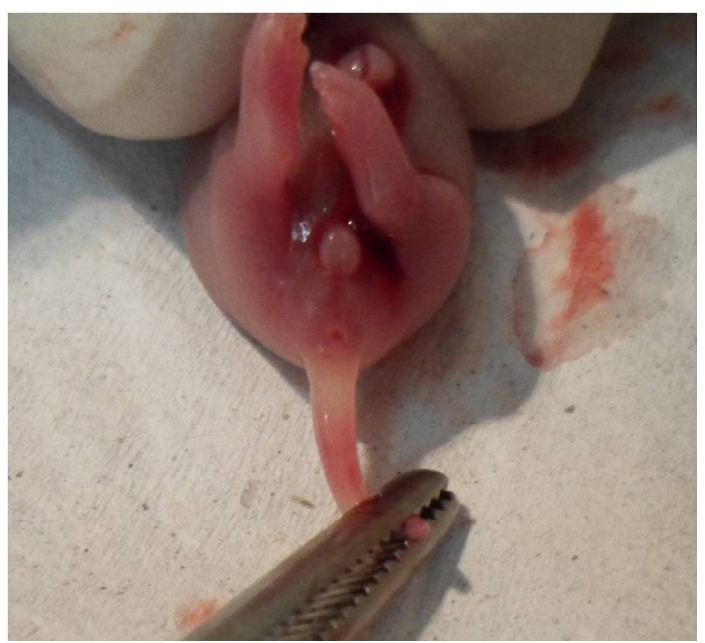

FIGURE 1 - No ARM - AF + ADR group.



FIGURA 2 - ARM ADR induced - ADR group.



FIGURA 3 - ARM ADR induced, limb and facial defects-ADR group.
Some others anomalies were observed. Limb and facial defects, coexisting or not with ARMs, were observed in both groups. There was no significant difference $(\mathrm{p}>0.05)$.

The thickness of anal stratified squamous epithelium (ASSE) and intestinal epithelium (IE) were analyzed (Table 2; Figures 4 and 5). Statistic significant differences were not observed on thickness of ASSE ( $>>0.05$ ). However, the thickness of IE was significantly enlarged when FA was given $(p<0.005)$.

TABLE 2 - Thicknes of ASSE and IE.

\begin{tabular}{cccc}
\hline Group & ASSE \pm SD $(\mu \mathrm{m})$ & IE \pm SD $(\mu \mathrm{m})$ & ARM $(\%)$ \\
\hline ADR & $25.98 \pm 0.74$ & $19.48 \pm 1.68$ & $65 \%$ \\
AF + ADR & $24.74 \pm 0.91$ & $24.80 \pm 0.81$ & $16 \%$ \\
\hline
\end{tabular}

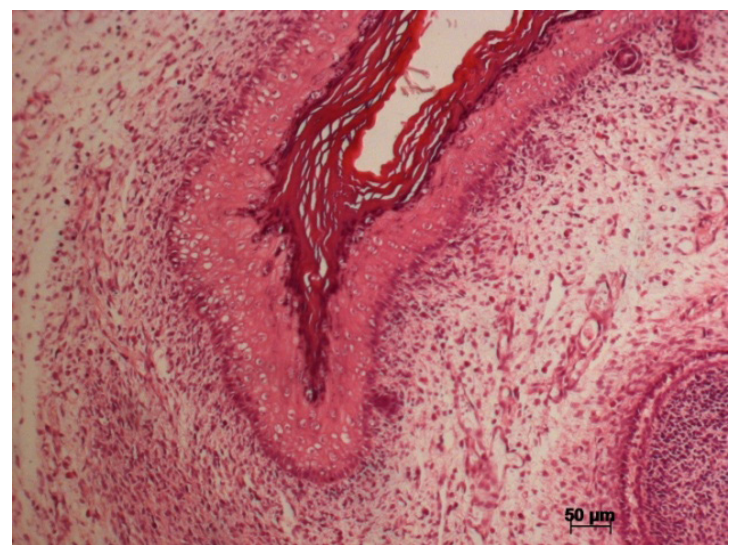

FIGURE 4 - Thickness of ASSE - ARM - ADR-group (x20).

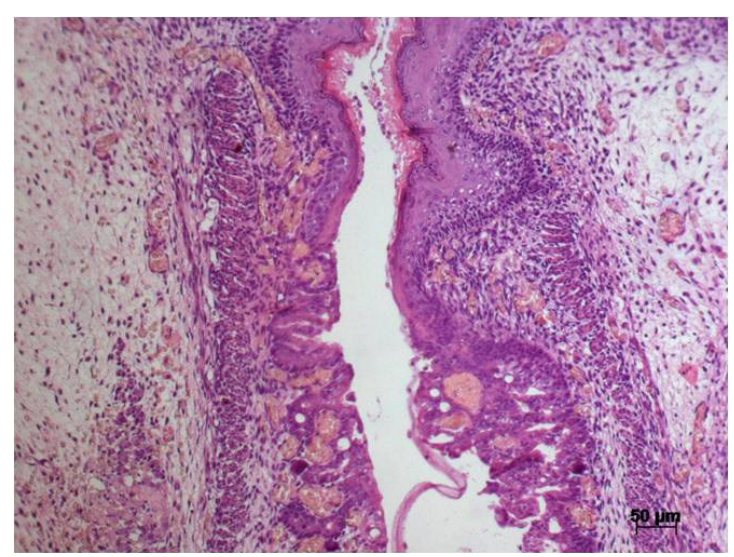

FIGURE 5 - Thickness of IE - No ARM - FA+ADR group (x 20).

\section{Discussion}

ARMs are among the most common congenital anomalies in humans. In male, rectourethral fistula has been the most usually 
presentation linked to ARMs, while vestibular fistula has been the most usually presentation in females. The most of them present as an isolated malformation, although it may be part of VACTERL anomalies. The term VACTERL represents vertebral, anorectal, cardiovascular, tracheal, esophageal, renal and limb anomalies.

Currently, PSARP ${ }^{2}$ has been performed throughout the world. This technique allowed better understanding of anorectal anatomy. Despite optimal surgical management, many patients reclaim of bowel and voiding dysfunction. These dysfunctions occur probably because no adequate repair for poorly developed muscles or nerves has been developed at this time.

ARMs pathogenesis and morphogenesis remains unclear. Various experimental models have been published using different animals. Rats are the most common animal used, including mutant mice. Different teratogenic drugs have induced ARMs in rats. Different models of foregut anomalies ADR-induced have been published $^{3-5}$.

Initially, $2 \mathrm{mg} / \mathrm{kg}$ of ADR were given on GD 6 through nine to establish an esophageal atresia experimental model ${ }^{6}$. This model had been changed, using ADR on GD 7, 8 and 9 (7), or using higher doses on GD 7 and $8^{3,4}$.

When using higher doses of ADR on GD 7 and 8, ARMs were induced in all fetuses. ARMs were associated with extensive bowel agenesis or with rectal atresia followed by blind-ended stratified squamous epithelium in some of those fetuses. Most of them had small or absent external genital tubercles and shortened tails $^{3}$. From this moment, this model became a well established an ARMs ADR-induced experimental model in rats.

Some others experimental models replicate the findings of ADR experimental model. Mutant mice with various defects in the Sonic hedgehog (Shh) signaling pathway exhibit aspectrum of distal hindgut defects mimicking human anorectal malformations. Shh null mice fail to develop an anus, rectum, and lower urinary tract, quite similar to ADR model ${ }^{8}$.

Abnormalities in the notochord were demosntrated in ADR model. A delayed separation of the notochord from the gut endoderm leads notochord to develop abnormal branches out toward the gut $^{7}$. Notochord remained tethered to the foregut with an increased dorsoventral diameter ${ }^{9}$. Was suggested a causative link between abnormalities of the notochord and hindgut malformations ${ }^{5}$ and the notochord may have a critical importance in the development of ARMs ${ }^{9}$. Sh $h$ signaling pathway is essential for normal patterning of the foregut and hindgut. A close relationship between $S h h$ expressing on notochord branches and on hindgut was reported ${ }^{5}$.
In this study, our group presents a different experimental model of AMRs ADR-induced. ARMs were induced using only one dose of ADR $(6 \mathrm{mg} / \mathrm{kg})$ on GD 8. In this modified model, $65 \%$ of ARMs were induced by ADR, not even close to previous results using 2 or 3 doses of $\mathrm{ADR}^{3-5}$. Our results are similar to experimental model of ARMs ethylenethiourea induced ${ }^{10-13}$. The mean weight of the fetuses of dams who received ADR was less than the fetuses of dams who received FA + ADR. The low weight of fetuses was also described by others authors ${ }^{14}$.

Postoperative anorectal function depends on many factors, such as pelvic floor muscles, innervation of pelvic floor muscles, and no spinal cord anomalies. Striated muscle complex (SMC) is one of the most important factors related to anorectal function. Various defects in SMC were described in ARMs, such as the increased distance between SMC and the perineal skin ${ }^{15}$.

Internal anal sphincter (IAS) is very important to continence. IAS is responsible for the normal rectal anal inhibitory reflex controlling the resting tonus in the anal canal and keeping the anus closed. These muscles are dysplastic in rats with $\mathrm{ARMs}^{16}$.

In this study, the thickness of ASSE was thick in ADR group and the thickness of IE was thin in ADR group. Folic acid did not modify significantly the thickness of ASSE. On the other hand, the thickness of IE was significantly thicker in FA+ADR group than in ADR group. Fetuses with ARMs presented both thickness of ASSE and IE smaller than normal rats, but it was not possible to prove by statistical analysis. This analysis was only able to compare entire groups, but not each fetus individually.

Folic acid or folate is the generic term of a water soluble $\mathrm{B}$ vitamin. Folic acid has low toxicity. The term folate refers to the deprotonated ion, while folic acid refers to the neutral molecule or the synthetic form of vitamin B. Folic Acid is more stable than folate.

Maternal FA deficiency was correlated with neural tube defects (NTD).FA provides well-documented benefit for the prevention of NTD and craniofacial defects. Currently, many countries recommend that all women planning or capable of pregnancy take a daily supplement containing $400-800 \mu \mathrm{g}$ of folic $\operatorname{acid}^{17-19}$

Few authors have studied the relationship between FA and ARMs, and their results are unclear. Some of them had not found any difference in development of ARMs when FA was taken ${ }^{20-22}$. On the other hand, other authors had related some protection of FA in development of $\mathrm{ARMs}^{23-25}$.

During folate metabolism, folate is converted by dihydrofolate reductase (DHFR) to tetrahydrofolate (THF), the naturally bioactive form. Methylenetetrahydrofolate 
reductase (MTHFR) catalyzes the conversion of THF to 5-methyltetrahydrofolate (5-MeTHF), the main form of folate in the blood circulation. Low enzyme activity of MTHFR reduces 5-MeTHF plasma levels, leading to increased levels of homocysteine. These changes have been related to neural tube defects. No relationship between ARMs and reduced enzyme activity of MTHFR was found ${ }^{22}$.

In this study, we were able to induce ARMs using a single dose of ADR. Nevertheless, the number of ARMs was lower when using a single injection than when using 2 or 3 injections. The effect of FA in this model is important to highlight, reducing significantly the incidence of ARMs from $65 \%$ to $16 \%(p=0.05)$. Further studies are necessary to explain how folic acid acts in this model.

\section{Conclusion}

Single dose of adriamycin on D8 was able to induce anorectal malformations. Folic acid reduces the number and enlarged the IE of ARMs ADR-induced.

\section{References}

1. Martins JL, Pinus J. Anomalías anorrectales: evaluación de resultados de su tratamiento quirúrgico en 162 niños tratados entre 1986 a 1999. Rev Cir Infant. 1999;9(4):221-6.

2. Peña A, Devries P. Posterior sagittal anorectoplasty: important technical considerations and new applications. J Pediatr Surg. 1982;17(6):796-811. doi: 10.1016/S0022-3468(82)80448-X.

3. Dawrant MJ, Giles S, Bannigan J, Puri P. Adriamycin produces a reproducible teratogenic model of vertebral, anal, cardiovascular, tracheal, esophageal, renal, and limb anomalies in the mouse. J Pediatr Surg. 2007;42(10):1652-8. doi: 10.1016/j.jpedsurg.2007.05.018.

4. Dawrant MJ, Giles S, Bannigan J, Puri P. Abnormal separation of the respiratory primordium in the adriamycin mouse model of tracheoesophageal malformations. J Pediatr Surg. 2007;42(2):37580. doi: 10.1016/j.jpedsurg.2006.10.011.

5. Sato H, Hajduk P, Furuta S, Wakisaka M, Murphy P, Puri P, Kitagawa $\mathrm{H}$. Effect of abnormal notochord delamination on hindgut development in the Adriamycin mouse model. Pediatr Surg Int. 2013;29(11):1209-16. doi: 10.1007/s00383-013-3386-5.

6. Diez-pardo BJA, Baoquan Q, Navarro C, Tovar JA. A new rodent experimental model of esophageal atresia and tracheoesophageal fistula: preliminary report. J Pediatr Surg. 1996;31(4):498-502. doi: 10.1016/S0022-3468(96)90482-0.

7. Gillick J, Mooney E, Giles S, Bannigan J, Puri P, Gittes G. Notochord anomalies in the adriamycin rat model: a morphologic and molecular basis for the VACTERL association. J Pediatr Surg. 2003;38(3):469-73. doi: 10.1053/jpsu.2003.50081.

8. Mo R, Kim JH, Zhang J, Chiang C, Hui CC, Kim PC. Anorectal malformations caused by defects in sonic hedgehog signaling. Am J Pathol. 2001;159(2):765-74. doi: 10.1016/S0002-9440(10)617476.

9. Qi BQ, Beasley SW, Frizelle FA. Evidence that the notochord may be pivotal in the development of sacral and anorectal malformations. J Pediatr Surg. 2003;38(9):1310-6. doi: 10.1016/ S0022-3468(03)00387-7.

10. Tang XB, Zhang J, Wang WL, Yuan ZW, Bai YZ. Spatiotemporal expression of $\mathrm{Cdx} 4$ in the developing anorectum of rat embryos with ethylenethiourea-induced anorectal malformations. Cells Tissues Organs. 2014;199(2-3):212-20. doi: 10.1159/000365965.

11. Tang XB, Zhang T, Wang WL, Yuan ZW, Bai YZ. Temporal and spatial expression of caudal-type homeobox gene-2 during hindgut development in rat embryos with ethylenethiourea-induced anorectal malformations. Cell Tissue Res. 2014;357(1):83-90. doi: 10.1007/ s00441-014-1858-0.

12. Macedo M, Martins JL, Meyer KF, Soares IC. Study of the density of ganglion cells in the terminal bowel of rats with anorectal malformations. Acta Cir Bras. 2007;22(6):441-5. PMID: 18235931.

13. Lemos SPP, Martins JL, Lemos PVRB, Silva SRG, Santos FL, Silva Jr VA. Abnormalities of digestive tract innervation in rat fetus treated with ethylenethiourea. Acta Cir Bras. 2012;27(3):244-50. PMID: 22460255.

14. Mortell A., O’Donnell A. M, Giles S, Bannigan J, Puri P. Adriamycin induces notochord hypertrophy with conservation of sonic hedgehog expression in abnormal ectopic notochord in the adriamycin rat model. J Pediatr Surg. 2004;39(6):859-63. doi: 10.1016/j.jpedsurg.2004.02.040.

15. Zhang SW, Bai YZ, Zhang SC, Wang DJ, Zhang T, Zhang D, Wang WL. Embryonic development of the striated muscle complex in rats with anorectal malformations. J Pediatr Surg. 2008;43(8):1452-8. doi: 10.1016/j.jpedsurg.2008.02.059.

16. Zhang SW, Bai YZ, Zhang D, Zhang T, Zhang SC, Wang DJ, Wang WL. Embryonic development of the internal anal sphincter in rats with anorectal malformations. J Pediatr Surg. 2010;45(11):2195202. doi: 10.1016/j.jpedsurg.2010.06.020.

17. Wolff T, Witkop CT, Miller T, Syed SB. Folic acid for the prevention of neural tube defects: U.S. preventive services task force recommendation statement. Ann Intern Med. 2009;150(9):626-31. doi: 10.7326/0003-4819-150-9-200905050-00009.

18. Wolff T, Witkop CT, Miller T, Syed SB. Folic acid for the prevention of neural tube defects: an update of the evidence for the U.S. preventive services task force. Ann Intern Med. 2009;150(9):632-9. doi: 10.7326/0003-4819-150-9-200905050-00010.

19. Bower C, D'Antoine H, Stanley FJ. Neural tube defects in australia: trends in encephaloceles and other neural tube defects before and after promotion of folic acid supplementation and voluntary food fortification. Birth Defects Res Part A - Clin Mol Teratol. 2009;85(4):269-73. doi: 10.1002/bdra.20536.

20. Källén B. Congenital malformations in infants whose mothers reported the use of folic acid in early pregnancy in Sweden. A prospective population study. Congenit Anom. 2007 ;47(4):119-24. PMID: 17988253.

21. van Rooij IA, Wijers CH, Rieu PN, Hendriks HS, Brouwers MM, Knoers NV, de Blaauw I, Roeleveld N. Maternal and paternal risk factors for anorectal malformations: a Dutch case-control study. Birth Defects Res A Clin Mol Teratol. 2010;88(3):152-8. doi: 10.1002/bdra.20649.

22. Wijers CHW, de Blaauw I, Zwink N, Draaken M, van der Zanden LFM, Brunner HG, Brooks AS, Hofstra RM, Sloots CE, Broens PM, Wijnen MH, Ludwig M, Jenetzky E, Reutter H, Marcelis CL, Roeleveld N, van Rooij IA. No major role for periconceptional folic acid use and its interaction with the MTHFR C677T polymorphism in the etiology of congenital anorectal malformations. Birth Defects Res Part A Clin Mol Teratol. 2014;100(6):483-92. doi: 10.1002/ bdra.23256.

23. Myers MF, Li S, Correa-villaseñor A, Li Z, Moore CA, Hong SX, Berry RJ. Folic acid supplementation and risk for imperforate anus 
in China. Am J Epidemiol. 2001;154(11):1051-6. doi: 10.1093/ aje/154.11.1051.

24. Czeizel AE, Tóth M, Rockenbauer M. Population-based case control study of folic acid supplementation during pregnancy. Teratology. 1996;53(6):345-51. PMID: 8910980.

25. Correa A, Gilboa SM, Botto LD, Moore CA, Hobbs CA, Cleves MA, Riehle-Colarusso TJ, Waller DK, Reece EA; National Birth Defects Prevention Study. Lack of periconceptional vitamins or supplements that contain folic acid and diabetes mellitusassociated birth defects. Am J Obstet Gynecol. 2012;206(3):218.e1-13. doi: 10.1016/j.ajog.2011.12.018.

\section{Correspondence:}

José Luiz Martins

Rua dos Otonis, 131

04025-000 São Paulo - SP Brasil

Tel./Fax: (55 11)5575-4761

jlmartins1@terra.com.br

Received: Sept 15, 2015

Review: Nov 17, 2015

Accepted: Dec 19, 2015

Conflict of interest: none

Financial source: none

${ }^{1}$ Research performed at Laboratory of Experimental Surgery, Universidade Federal de São Paulo (UNIFESP), Brazil. Part of Master degree thesis, Postgraduate Program in Interdisciplinary Surgical Science, UNIFESP. Tutor: José Luiz Martins. 